POSITRON LIEETIMES IN VOIDS AND OTHER DIFFCTS IN ANNTEALED, NEUTRON-IRRADIATED ALUMLNUM:

BV acceptance of this article, the pultisher or recipient ecknowlertges the U.S. Government's right to rotain a nonexclusiva, coyolty-frup license in and to any conyriglit covering the articls.

J. D. McGervey and V. W. Lindbergt

Department of Physics, Case Western Reserve Universtey Cleveland, Ohio 44106 USA

and

R. W. Hendricks

Metals and Ceramics Division, Oak Ridge National Laborato-

The tepoes ens porice sponbored uy the Uniled States Covernmertit. Neither the Uatied Statea nat ithe United Stater inowy

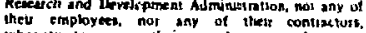

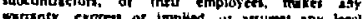

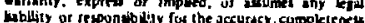
of uxefulnes of any infos metion, apporates, product at

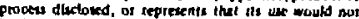
infringer privalely ommed nahit.

Oak Ridge, Tennessee 37830 USA

ABSTRACT

We have measured positron lifetimes in neutron-irradiated high-purity aluminum single crystals, ano have performed companion small-angle $x$-ray scattering experiments to determine the radius of gyration and volume fraction of radiation-induced voids. The lifetime data are consistent with a model in which positrons are trapped both in voids and in other defects which are tentatively identified as vacancy clusters bound to transmutation-produced silicon. The Iffetime In the latter defects increased from $230 \mathrm{psec}$ to $430 \mathrm{psec}$ as the voids annealed out (around $306^{\circ} \mathrm{C}$ ), suggesting that the clusters grow in size as voids disappear. The lifetime in voids remained constant at $(550 \pm 30)$ psec.

\title{
INTRODUCTION
}

Positron techniques were first used to study neutron-irradiation induced voids in molybdenum $[1,2]$ and in aluminum $[3,4]$. In this paper we present a correlation of positron lifetimes with void parameters as determined by sma11-. angle $x$-ray scattering in irradiated aluminum. Our samples were anzealed at successively higher temperatures, witt data being collected after some of these temperatures. The present experiments are a continuation of our studies aimed at eluciduting the mechanisms of nucleation and growth and the properties of volds in neutron-irradiated aluminum single crystals. Earlier work with transmission electron microscopy [5], smal1-angle x-ray scattering [5], sma11-angle neutron scattering $[6,7]$, and posftron annihilation $[3,4]$ has been reported previous $1 y$. An expanded report of the present research, including results from angular correlation of annihilation radiation, will appear elsewhere [8].

*Research sponsored in part by the US National Science Foundation and the Energy Research and Development Alministration under contract with the Union Carbide Corporation.

fPresent address: Hartwick College, Oneonta, New York 13820 USA. 


\section{EXPSRTMENTAL TECHNIQ̨UE}

\section{Sample Preparation}

The sample, a $31 \mathrm{~mm} \times 6 \mathrm{~mm} \times 0.9 \mathrm{~m}$ single crystal grown from $99.9999+\%$ starting material, * was prepared as one of the sequence described by Epperson et al.[5]. It was irradiated in the hydraulic tube of the Oak Ridge High Flux Isotope Reactor in contact with the cooling water at a temperature of $55 \pm 5^{\circ} \mathrm{C}$ to a thermal fluence of $1.17 \times 10^{22}$ neutrons $/ \mathrm{cm}^{2}(\mathrm{E}<25.3 \mathrm{MeV}$ ) and a fast fluence of $4.96 \times 10^{21}$ neutrons $/ \mathrm{cm}^{2}(E>0.1 \mathrm{meV})$.

Pieces of the speclmen were annealed at successively higher temperatures in an attemp: to vary the concentration and size of the voids. Isochronal one-hour anneals were done in $25^{\circ} \mathrm{C}$ steps between 150 and $275^{\circ} \mathrm{C}$. Thereafter, 20-minute isochronal anneals were done in $6^{\circ} \mathrm{C}$ steps up to a temperature of $319^{\circ} \mathrm{C}$, and a final one-hour anneal was done at $350^{\circ} \mathrm{C}$. The annealing was done in a wellregulated tube furnace under an argon atmosphere, and the temperature was maintained constant to within $\pm 1^{\circ} \mathrm{C}$.

\section{Smal1-Angle X-Ray Scattering}

We have characterized the void distributions in the specimens by determining the sample radius of pyration $\left(R_{g}\right)$ and swelling $(\Delta V / V)$ or the oRrL 10-meter small-angle x-ray scattering spectrometer [9]. This device utilizes a 6 kflowatt rotating anode $x$-ray source, pin-hole collimation $(1 \mathrm{~mm} \times 1 \mathrm{~min}$ square slit at the specimen), and a $20 \mathrm{~cm} \times 20 \mathrm{~cm}$ two-dimensional position-senstive proportional counter with up to $200 \times 200$ resolution elements ( $1 \mathrm{~mm}$ spatial resolution FWHM). The measurements were obtained in $4000 \mathrm{sec}$ per sample. The analysis of the data followed the procedures described earlier [6].

\section{Lifetime Measurements}

Lifetime spectra were taken after the anneal to $250^{\circ} \mathrm{C}$ and after all anneals above $293^{\circ} \mathrm{C}$. A sodium-22 source mounted on $3.8 \mu \mathrm{m}$ Mylar film was sandriched between two pieces of the sample. This was viewed by Pilot $U$ scintillators mounted on XP1021 phototubes. The scintillators were in the shape of truncated cones $25 \mathrm{~mm}$ high, $25 \mathrm{~mm}$ in base diameter, and $6.4 \mathrm{~mm}$ in apex diameter. A standard fast-slow electronic system utilized constant-fraction fast discriminators and an ORTEC 437 TAC to give timing information, and DDL amplifiers and timing single channel analyzers to give energy information to gate the multichannel analyzer.

*obtained from Cominco American Inc., Spokane, WN, USA. 
The time calibration was $11.15 \mathrm{psec} / \mathrm{channel}$ as determined by an ORTEC 462 time calibrator. Each run lasted about $6 \times 10^{5}$ seconds; drifts in the peak channel during the rum were detected and compensated for.

The overall prompt resolution of our system was determined with a Cobalt-60 source. When the energy windows on the SCA's were set for the upper $20 \%$ of the cobalt $\gamma$-ray spectrum, the FNHM of the resolution curve was 200 psec. When $20 \%$ windows were set at the experimental settings, the FWHM was 340 psec. The shape of the resolution curve matched a Gaussian quite wel.1.

THEORY

The positron lifetime spectrum from the unannealed sample shows three exponentially-decaying components, which may be attributed to annililations in the bulk and in two distinct types of defects. In the simplest possible trapping mode], the defects trap the positrons with trapping rates $\alpha$ and $\beta$, respectively, and no detrapping occurs. If the numbers of positrons in the bulk metal and the two typesof defect are $N_{1}, N_{2}$, and $N_{3}$, respectivelv, and the respective annihilation rates are $\lambda_{f}, \lambda_{2}$, and $\lambda_{3}$, solution of the rate equations, under the Initial conditions $N_{1}=3$. and $N_{2}=N_{3}=0, y$ lelds

$$
\mathrm{N}=\mathrm{N}_{1}+\mathrm{N}_{2}+\mathrm{N}_{3}=\mathrm{Ae} \mathrm{e}^{-\lambda_{1} t}+\mathrm{Be} \mathrm{e}^{-\lambda_{2} t}+\mathrm{Ce}-\lambda_{3} t
$$

with

$$
\alpha=B\left(\lambda_{1}-\lambda_{2}\right), \quad B=c\left(\lambda_{1}-\lambda_{3}\right)
$$

and

$$
\lambda_{\mathbf{f}}=\lambda_{1}-\alpha-\beta,
$$

where $\lambda_{1}$ is the total disappearance rate of positrons from the bulk; that is $\mathrm{dN}_{1} / \mathrm{dt}=-\lambda_{1} \mathrm{~N}_{1}$.

\section{RESULTS AND DISCUSSION}

Small-angle $x$-ray scattering showed that (i) the voids annealed out between $306^{\circ} \mathrm{C}$ and $319^{\circ} \mathrm{C}$, and $(i i)$ the radius of gyration remained constant at $220 \AA$ to $300^{\circ} \mathrm{C}$ then increased to $272 \AA$ by $319^{\circ} \mathrm{C}$. However, analysis of the shape of the scattering curve outside the Guinier region suggests (i) the shape of the void-size distribution curve or (ii) the space-average void shape changed during annealing. It is not possible to distinguish between these possibilities with SAXS. Finally, the temperature range where voids anneal out observed in this work $\left(306-319^{\circ} \mathrm{C}\right)$ is somewhat higher than observed by Epperson et al. [5]. 
The lifetine data were fitted by a routine similar to that described by Kirkegaard and Eldzup [10]. For annealing temperatures below $312^{\circ} \mathrm{C}$ three exponentialsi flus a source component were necessary for a good $\mathrm{fit}$. At and above $312^{\circ} \mathrm{C}$, two-exponential fits plus a souxce component were sufficient. Results for all the runs are shown $\mathrm{I}_{11} \mathrm{Fig}$. $1_{1}$, where the reciprocals of the rates $\lambda_{f}, \lambda_{2}$, and $\lambda_{3}$ are plotted as mean lifetimes.

The mean ifferime of the third component remained roughly constant at 550 psec while its intensity decreased with increasing annealing temperature, disappearing at $312^{\circ} \mathrm{C}$. At this temperature, the SAXS results show that the voids have essentially disappeared. Thus we conelude that this component results from annihilations in surface states in voids as suggested by Hodges and stott [11]. At the maximum vold concentration, about $50 \%$ of the positrons annihilated in the vold state.

The lifetime in the second type of defect shows much more variation. It increases from $230 \mathrm{psec}$ to $430 \mathrm{psec}$ while the void component is disappearing, and then slowly decreases. The intensity of this component also increases as the voids disappear, and then decreases. 'This type of defect persists at high annealing temperatures.

The behavior of this component may be explained by reference to siliconvacancy c isters. An estimated $1900 \mathrm{Dpm} S i$ was produced by the reaction ${ }^{27} \mathrm{Al}(\mathrm{n}, \gamma)$ with thermal neutrons followed by a $B^{-}$decay to ${ }^{2} \mathrm{si}$. The solubility of $S i$ in A]. is very smal1 - less than $1 \mathrm{ppm}$ at the irradiation temperature of $\sim 55^{\circ} \mathrm{C}$. It has been observed by TEM that voids in neutron-irradiated aluminum contaln silicon precipitates [.22], and some stlicon is believed to be spread over the surface of the void [7]. In the present case, the process of precipitation of supersaturated $\mathrm{Si}$ is complicated by 1 ts time-dependent production rate by thermal neutrons as well as by the continuous flux of excess vacancies and interstitials resulting from radiation effects. However, some insight can be gained by qualitative comparisons to work on the nature of indium-vacancy clusters in dilute Al(In) alloys $[13,1 ;]$. This showed that, at least in dilute $\mathrm{Al}$ ( $\mathrm{In})$, the distribution of vacancies, impurity atoms, impurity-vacancy pairs, and impurity-vacancy clusters (assumed to be triplets) could be analyzed in terms of the ratio $\mathbf{C}_{\mathbf{v}_{0}} / \mathrm{C}_{\mathbf{i}_{0}}$ (where $\mathrm{c}_{\mathrm{v}_{0}}$ is the total vacancy concentration and $\mathrm{C}_{\mathbf{i}_{0}}$ is the total impurity concentration). The arguments concerning the nature of the defects should qualitatively apply to $\mathrm{Al}(\mathrm{Si})$ alloys, because the impurity-vacancy binding energy is high and the impurity solubility is low in both alloys. During irradiation $\mathrm{C}_{v_{0}} \gg \mathrm{C}_{\mathbf{I}_{0}}$, and virtually all of the impurities were assoclated in vacancy-impurity complexes which had a relatively high binding energy. 
At the erid of irradtation, the concertration of vacancies in the matrix (not including those already associated with voids) becomes the thermal equilibrium value for the alloy, and the ratio $\mathrm{C}_{\mathrm{v}_{0}} / \mathrm{C}_{\mathrm{v}_{i}}$ must decrease significantly. Here, the structure shifts to one of a low concentration of complexes, with most defects of the vacancy-1mpurity dipole type. Thus, at the end of irradiation, in addition to the known voids at which the large excess of $\mathrm{Si}$ is precipitated (both on the void surface [7] and in the void comers $[5,12]$ ), we would expect the soluble Si to be present mostly in Si-vacancy pairs and some iarger clusters. We suggest that these clusters are the trapping sites for the 230 psec component.

Because of the high vacancy-impurity binding energy, and its effect on lowering the surface energy of voids in aluninum [7], the silicon on the vold surface stabilizes the void and makes it resistant to annealing. However, as the annealing temperature is increased, the solubility limit of Si increases, and finally the voids and their associated Si precipitates go into solution. It is significant that the temperature at which voids anneal out $\left(2310^{\circ} \mathrm{C}\right.$ in this stury) is approximately the temperature of the solubility limit at this composition.* During annealing-out of volds, the vacancy concentration, as well as the silicon concentration, increases in the matrix. Because there are many more vacancies than there are $S i$ atoms in a void, the $c_{v 0} / C_{i_{0}}$ ratio in the matrix again increases thus shifting the system towards a state in which there are an increasing number of silicon-vacancy complexes. An increase in the size of the clusters would explain the increase in $1 / \lambda_{2}$ with increasing annealing temperature. It is interesting that our values of $1 / \lambda_{2}$ range from $230 \mathrm{psec}$ to $430 \mathrm{psec}$, while Jena and Singwi. [15] have calculated values of 210 psec for monovacancies in aluminum and 399 psec for 8-vacancy clusters. An increase in the number of clusters should be reflected in an increase in the trapping rate $\alpha$ to clusters. From $250^{\circ} \mathrm{C}$ to $300^{\circ} \mathrm{C} \alpha$ decreases, suggesting that the number of clusters is being reduced by combination of small ones into larger ones. Above $300^{\circ} \alpha$ increases somewhat as virtually all of the silicon goes back into solution thus increasing the number as well as the size of Si-vacancy complexes. (The presence of silicon in these clusters cannot at present be verified by positron techniques.)

*This argument also explains the slight increase $\left(10-20^{\circ} \mathrm{C}\right)$ in the temperature at which voids anneal out as determined here compared to the lower tenperatures found in crystals irradiated to lower fluences and thus containing less transmutation-produced Si. 
REFERENCES

[1] R.M.J. Cotteri11, I. K. Mackenzie, L. Smedskjaer, G. Trumpy, and J.H.o. Traff, Nature 239 (1972) 99.

[2j O. E. Mogensen, K. Petersen, R.M.J. Cotterill, and B. Yudson, Nature 239 (1972) 98.

[3] H. Triftshäuser, J. D. McGervey, and R. W. Hendricks, Phys. Rev. B9 (1974) 3321.

[4] K. Petersen, N. Thrane, G. Trumpy, and R. W. Hendricks, Applied Physics, to be published.

[5] J. E. Epperson, R. W. Hendricks, and K. Farre11, PhiZ. Mag. 30 (1974) 803.

[6] R. W. Hendri.cks, J. Schelten, and W. Schmatz, Phi . Mag. 30 (1974) 819.

[7] R. W. Hendricks, J. Schelten, and G. Lippmann, submitted to Phil. Mag.

[8] V. W. Lindberg, J. D. McGervey, and R. W. Hendricks, submitted to Phiz. Mag.

[9] R. W. Hendricks, submitted to J. Appl. CrystaZlogr.

[10] P. Kirkegaard and M. Eldrup, Computer Phys. Common. 3 (1972) 240.

[11] C. H. Hodges and M. J. Stott, Soïid State Commu. 12 (1973) 1153.

[12] A. Jostsons, E. L. Long, J. O. Stiegler, K. Farre11, and D. N. Braski, Radiation Induced Voids in Metals, (J. W. Corbett and L. C. Ianniello, eds.) Proc. Int. Conf. Albany (1971).

[13] J. E. Epperson, P. Fürnrohr, and V. Gerold, PhiZ. Mag. 29 (1974) 1189.

[14] J. E. Epperson, P. Fürnrohr, and V. Gerold, Mat. Sci. Eng. 19 (1975) 95.

[i5] P. Jena and K. S. Singwi, private communication.

\section{FIGURE CAPTION}

Meanlives and intensities of the exponential components $A(0), B(\Delta)$, and $C(x)$, versus isochronal annealing temperature. Where two points are shown for $300^{\circ} \mathrm{C}$, the lower was taken after 40 minutes of annealing, and the higher after 60 minutes of annealing. The lines merely indicate the trend of the points. 

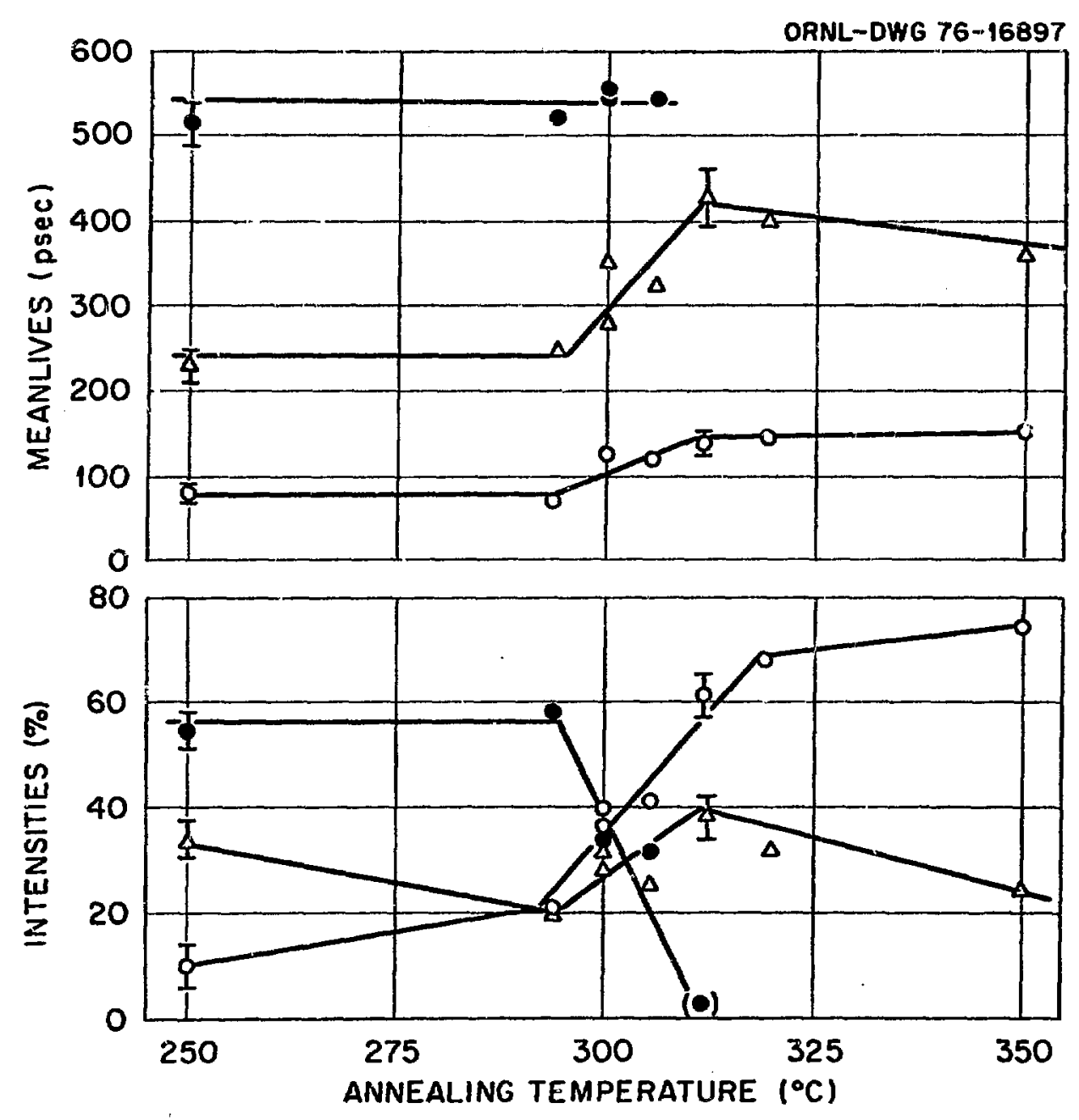